\title{
Thyroid hormone actions are temperature-specific and regulate thermal acclimation in zebrafish (Danio rerio)
}

\author{
Alexander G Little ${ }^{1 *}$, Tatsuya Kunisue ${ }^{2}$, Kurunthachalam Kannan ${ }^{2,3}$ and Frank Seebacher ${ }^{1}$
}

\begin{abstract}
Background: Thyroid hormone (TH) is best known for its role in development in animals, and for its control of metabolic heat production (thermogenesis) during cold acclimation in mammals. It is unknown whether the regulatory role of $\mathrm{TH}$ in thermogenesis is derived in mammals, or whether $\mathrm{TH}$ also mediates thermal responses in earlier vertebrates. Ectothermic vertebrates show complex responses to temperature variation, but the mechanisms mediating these are poorly understood. The molecular mechanisms underpinning $\mathrm{TH}$ action are very similar across vertebrates, suggesting that TH may also regulate thermal responses in ectotherms. We therefore aimed to determine whether TH regulates thermal acclimation in the zebrafish (Danio rerio). We induced hypothyroidism, followed by supplementation with 3,5-diiodothyronine $\left(T_{2}\right)$ or 3,5,3'-triiodothyronine $\left(T_{3}\right)$ in zebrafish exposed to different chronic temperatures. We measured whole-animal responses (swimming performance and metabolic rates), tissue-specific regulatory enzyme activities, gene expression, and free levels of $T_{2}$ and $T_{3}$.

Results: We found that both $T_{3}$ and the lesser-known $T_{2}$, regulate thermal acclimation in an ectotherm. To our knowledge, this is the first such study to show this. Hypothyroid treatment impaired performance measures in cold-acclimated but not warm-acclimated individuals, whereas supplementation with both TH metabolites restored performance. TH could either induce or repress responses, depending on the actual temperature and thermal history of the animal.

Conclusions: The low sensitivity to TH at warm temperatures could mean that increasing temperatures (that is, global warming) will reduce the capacity of animals to regulate their physiologies to match demands. We suggest that the properties that underlie the role of TH in thermal acclimation (temperature sensitivity and metabolic control) may have predisposed this hormone for a regulatory role in the evolution of endothermy.
\end{abstract}

Keywords: Thyroid hormone, Zebrafish, Temperature, Cold acclimation, Hypothyroid, Ectotherm, Metabolism, Thermal plasticity, Thermal response

\section{Background}

During thermal acclimation, ectotherms can shift their reaction norms by modifying the thermal sensitivities of their metabolic and other physiological pathways. This process can be mediated by changes in enzyme concentrations and mitochondrial biogenesis, modification of cell and mitochondrial membranes, and conformational changes that optimize enzyme efficiencies at different temperatures [1-3]. Despite the importance of acclimation

\footnotetext{
*Correspondence: alit2851@uni.sydney.edu.au

'School of Biological Sciences, A08 University of Sydney, Science Road, Sydney, NSW 2006, Australia

Full list of author information is available at the end of the article
}

for physiology, ecology, and conservation, the overarching mechanisms governing this process in ectotherms remain unknown [3]. We hypothesize that thyroid hormone (TH) regulates the thermal-acclimation response. Testing this hypothesis is important to understand how animals respond to temperature change. It is also important in an evolutionary context, because the ancestral function(s) of $\mathrm{TH}$ may have predisposed it for its central regulatory role in the evolution of endothermy.

TH has garnered much attention for its roles in metabolic heat production (thermogenesis) and energy expenditure [4-8] in mammals, which could be exploited for the treatment of diseases including obesity, type 2

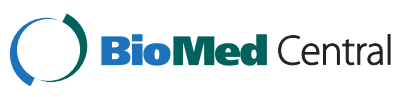


diabetes, and metabolic syndromes [9-15], but the complexity of the TH system is far from resolved. Several $\mathrm{TH}$ metabolites can stimulate physiological responses through a wide range of signaling pathways that are subject to many levels of biological regulation [16-21]. In vertebrates, $\mathrm{TH}$ is produced in the thyroid gland primarily as thyroxine $\left(\mathrm{T}_{4}\right)$, and is metabolized to $3,5,3^{\prime}$ triiodothyronine $\left(\mathrm{T}_{3}\right)$ and 3,5-diiodothyronine $\left(\mathrm{T}_{2}\right)$ by deiodinase enzymes (D1, D2 and D3) in peripheral tissues [22]. Other $\mathrm{TH}$ isomers exist, but are either physiologically inactive or have very low activity [23]. $\mathrm{T}_{3}$ was originally believed to be the only physiologically active $\mathrm{TH}$ because of its unique affinity for $\mathrm{TH}$ receptors, which regulate the expression of target genes transcriptionally by binding to thyroid response elements (TREs) in their promoters [23]. Recently, however, $\mathrm{T}_{2}$ was also found to stimulate metabolism, but through non-genomic (posttranscriptional) pathways, which are as yet poorly understood [23]. $\mathrm{T}_{2}$ acts at different cellular levels (including plasma membrane, cytosol, and mitochondria) and elicits much quicker responses than $T_{3}[18,23]$. Although $T_{2}$ has been shown to stimulate metabolism, its physiological relevance is still in question [23].

$\mathrm{TH}$ is ubiquitous across all vertebrates [4,24], and even stimulates growth and development in many invertebrate groups [25-32]. Interestingly, TH can produce drastically different responses in different animal groups [24,33]. Generally, TH regulates growth and development in vertebrates and invertebrates, but additionally regulates metabolism and thermogenesis during cold exposure in mammals. However, these functionally distinct roles are underpinned by overlapping physiological and biochemical pathways [33]. Energy metabolism and its control are highly conserved in vertebrates [34], but it is unknown whether the role of TH in mediating thermal responses is independently derived in mammals, or whether it is also present in earlier vertebrates. In all animals, biochemical pathways are sensitive to acute changes in temperature. However, endotherms and many ectotherms regulate, or acclimate, their metabolism to compensate for longer-term (days to weeks) thermal variation in their environments. We hypothesize that, as in endotherms, TH regulates these physiological responses of ectotherms to chronic changes in their thermal environment.

Specifically, we assessed the metabolic role of TH during thermal acclimation in the zebrafish (Danio rerio). The zebrafish was chosen as a model because fish occupy an early position in vertebrate evolution, and the zebrafish in particular has become an important biomedical model for thyroid-related disease, including obesity, cardiovascular disease, and diabetes [35,36]. We used a multi-factorial experimental design in which we induced hypothyroidism, followed by supplementation with $\mathrm{T}_{2}$ and $\mathrm{T}_{3}$ (plus normal thyroid controls) in zebrafish exposed to different chronic and acute temperature combinations. We measured whole-animal responses (swim performance, metabolic rates, and metabolic scope), and determined tissuespecific protein function (activities of regulatory enzymes), metabolic gene expression (liver and muscle), and levels of free $T_{2}$ and $T_{3}$ to determine whether $T H$ is the mechanism that drives thermal acclimation in ectotherms. We hypothesized that hypothyroidism would impair acclimation responses, and that supplementation with $\mathrm{T}_{3}$ and $\mathrm{T}_{2}$ would restore acclimation in hypothyroid fish.

\section{Results}

\section{Thyroid hormone levels}

Levels of both $T_{3}$ and $T_{2}$ were lower in muscle tissue from cold-acclimated fish (Table 1). The TH levels in cold-acclimated hypothyroid fish supplemented with $\mathrm{T}_{3}$ and $\mathrm{T}_{2}$ verified that our hypothyroid and supplementation treatments were effective (Table 2).

\section{Effects of cold acclimation}

Cold acclimation significantly increased sustained swimming performance (critical sustained swim speed; $U_{\text {crit }}$ ) at acute test temperatures of both $18^{\circ} \mathrm{C}$ and $28^{\circ} \mathrm{C}$ (Figure 1A; Table 3; see Additional file 1: Table S1). Cold-acclimated fish (kept for 3 weeks at $18^{\circ} \mathrm{C}$ ) compensated for the limiting effect of low temperature, and swam as well at the $18^{\circ} \mathrm{C}$ acute test temperature as warm-acclimated (3 weeks at $28^{\circ} \mathrm{C}$ ) fish did at a test temperature of $28^{\circ} \mathrm{C}$.

There was no effect of acclimation temperature on resting metabolic rate, but cold acclimation significantly increased active metabolic rate and, hence, metabolic scope (Figure 1B-D; Table 3). There was a significant increase in maximal lactate dehydrogenase (LDH) activity in the cold-acclimated fish, but no effect of acclimation treatment on maximal citrate synthase (CS) or cytochrome c oxidase (COX) activities (Figure 1E-G; Table 3; see Additional file 1: Table S1). Cold-acclimation significantly increased transcript levels of the transcriptional

Table 1 Muscle-specific levels of $T_{2}$ and $T_{3}$ in cold-acclimated and warm-acclimated normal thyroid zebrafish

\begin{tabular}{|c|c|c|c|c|}
\hline \multirow[b]{2}{*}{ Sample } & \multicolumn{2}{|c|}{ Cold-acclimated } & \multicolumn{2}{|c|}{ Warm-acclimated } \\
\hline & $\mathrm{T}_{2}, \mathrm{ng} / \mathrm{g}$ & $T_{3}, n g / g$ & $\mathrm{~T}_{2}, \mathrm{ng} / \mathrm{g}$ & $T_{3}, \mathrm{ng} / \mathrm{g}$ \\
\hline 1 & 2.45 & 3.35 & 3.11 & 6.23 \\
\hline 2 & $<1.00$ & $<1.00$ & 1.25 & 9.57 \\
\hline 3 & 1.91 & 2.83 & 1.56 & 7.05 \\
\hline 4 & 4.27 & 7.00 & 2.96 & 28.70 \\
\hline 5 & 1.40 & 1.95 & 1.70 & 39.10 \\
\hline 6 & $<1.00$ & 1.54 & 5.25 & 531.00 \\
\hline Mean & 1.71 to 2.00 & 2.80 to 2.95 & 2.64 & 103.61 \\
\hline SEM & 0.21 & 0.36 & 0.25 & 34.97 \\
\hline
\end{tabular}


Table 2 Muscle-specific levels of $T_{2}$ and $T_{3}$ in cold-acclimated hypothyroid zebrafish supplemented with $\mathrm{T}_{2}$ or $\mathrm{T}_{3}$

\begin{tabular}{llllll}
\hline & \multicolumn{2}{l}{$\mathbf{T}_{\mathbf{2}}$-supplemented } & & \multicolumn{2}{l}{$\mathbf{T}_{\mathbf{3}}$-supplemented } \\
\cline { 2 - 3 } \cline { 5 - 6 } $\mathbf{T}_{\mathbf{2}}, \mathbf{n g} \mathbf{g}$ & $\mathbf{T}_{\mathbf{3}}, \mathbf{n g} \mathbf{g}$ & & $\mathbf{T}_{\mathbf{2}}, \mathbf{n g} \mathbf{g}$ & $\mathbf{T}_{\mathbf{3}} \mathbf{n} \mathbf{g} \mathbf{g}$ \\
\hline 1 & 2.66 & 0.00 & 0.00 & 107.00 \\
2 & $<5.00$ & 0.00 & & 0.00 & 40.80 \\
3 & 1.73 & 0.00 & 0.00 & 52.90 \\
4 & $<5.00$ & 0.00 & 0.00 & 30.60 \\
5 & $<5.00$ & 0.00 & 0.00 & 40.00 \\
6 & $<5.00$ & 0.00 & 0.00 & 63.10 \\
7 & 56.50 & $<1.00$ & 0.00 & 147.00 \\
8 & 52.10 & 1.97 & & 0.00 & 77.00 \\
9 & 44.00 & 1.75 & & $\mathrm{NA}$ & $\mathrm{NA}$ \\
Mean & 17.50 to 19.70 & 0.42 to 0.52 & 0.00 & 69.80 \\
SEM & 2.80 & 0.09 & 0.00 & 4.95 \\
\hline
\end{tabular}

Abbreviations: NA, not applicable. coactivators PGC1 $\alpha$ and PGC1 $1 \beta$, their target transcription factors PPAR $\delta$, NRF1, and NRF2b, subunits of the mitochondrial enzymes COX (COX VB2 and COX II), and $\mathrm{F}_{\mathrm{o}} \mathrm{F}_{1}$-ATPase (ATPase A, ATPase B, and ATPase 8/6) in muscle, and PGC1 $\alpha$, NRF1, NRF2b, COX VB2, ATPase A, and ATPase B in liver (Figure 1H,I; Table 4; Table 5; see Additional file 1: Table S1).

The effects of hypothyroid treatment on responses that acclimated

Hypothyroid treatment significantly decreased the sustained swim speed in the cold-acclimated fish, but it had no effect on swimming performance in the warmacclimated fish (Figure 2A; Table 3; see Additional file 1: Table S1). Hypothyroid treatment significantly decreased active metabolic rate and metabolic scope at both acclimation temperatures (Figure 2B,C; Table 3). Hypothyroid treatment significantly decreased $\mathrm{LDH}$ activity in muscle of cold-acclimated fish but it had no effect on warm-acclimated fish (Figure 2D; Table 3; see Additional file 1: Table S1). There was also a significant interaction

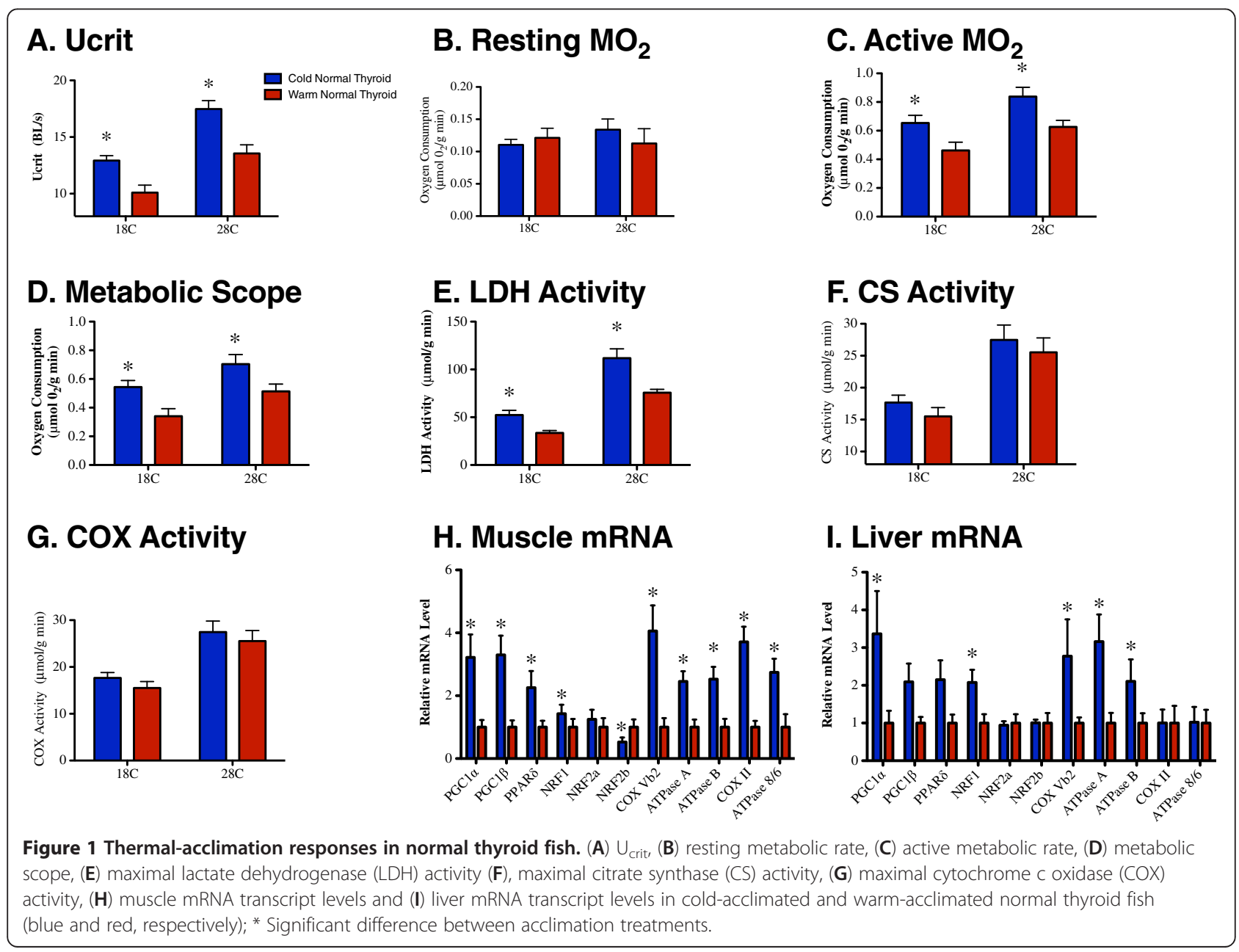


Table 3 Three-way permutational multivariate analysis of variance (PERMANOVA) results comparing parameters between cold-acclimated and warm-acclimated normal thyroid and hypothyroid fish

\begin{tabular}{|c|c|c|c|c|c|c|c|}
\hline & $A T^{a}$ & $\mathrm{H}^{\mathrm{b}}$ & $\mathrm{TT}^{\mathrm{c}}$ & $\mathrm{AT}^{\mathrm{a}} \times \mathrm{H}^{\mathrm{b}}$ & $\mathrm{AT}^{\mathrm{a}} \times \mathrm{TT}^{\mathrm{c}}$ & $\mathrm{H}^{\mathrm{b}} \times \mathrm{TT}^{\mathrm{c}}$ & $\mathrm{AT}^{\mathrm{a}} \times \mathrm{H}^{\mathrm{b}} \times \mathrm{TT}^{\mathrm{c}}$ \\
\hline \multicolumn{8}{|c|}{$\bar{U}_{\text {crit }}{ }^{d}$} \\
\hline$F$ & 5.319 & 12.900 & 14.768 & 5.711 & 0.0088 & 2.079 & 0.838 \\
\hline d.f & 1,69 & 1,69 & 1,69 & 1,69 & 1,69 & 1,69 & 1,69 \\
\hline P & $0.014^{*}$ & $<0.001^{* *}$ & $<0.001^{* *}$ & $0.017^{*}$ & 0.883 & 0.121 & 0.351 \\
\hline \multicolumn{8}{|c|}{ RMR } \\
\hline$F$ & 3.767 & 1.216 & 3.069 & 1.153 & 0.427 & 4.479 & 2.411 \\
\hline d.f & 1,59 & 1,59 & 1,59 & 1,59 & 1,59 & 1,59 & 1,59 \\
\hline P & $0.031^{*}$ & 0.273 & 0.048 & 0.297 & 0.653 & $0.032^{*}$ & 0.103 \\
\hline \multicolumn{8}{|c|}{ AMR } \\
\hline$F$ & 12.790 & 8.354 & 12.430 & 0.567 & 1.064 & 0.112 & 0.200 \\
\hline d.f & 1,59 & 1,59 & 1,59 & 1,59 & 1,59 & 1,59 & 1,59 \\
\hline P & $<0.001^{* *}$ & $0.004^{* *}$ & $<0.001^{* *}$ & 0.471 & 0.305 & 0.829 & 0.717 \\
\hline \multicolumn{8}{|l|}{ MS } \\
\hline$F$ & 8.488 & 9.140 & 8.251 & 1.280 & 0.772 & 0.352 & 1.031 \\
\hline d.f & 1,59 & 1,59 & 1,59 & 1,59 & 1,59 & 1,59 & 1,59 \\
\hline$P$ & $0.004^{* *}$ & $0.004^{* *}$ & $0.007^{* *}$ & 0.247 & 0.371 & 0.637 & 0.293 \\
\hline \multicolumn{8}{|c|}{$\mathrm{LDH}^{\mathrm{e}}$} \\
\hline$F$ & 11.547 & 0.642 & 145.460 & 5.611 & 3.886 & 0.291 & 2.346 \\
\hline d.f & 1,72 & 1,72 & 1,72 & 1,72 & 1,72 & 1,72 & 1,72 \\
\hline$P$ & $<0.001^{* *}$ & 0.445 & $<0.001^{* *}$ & $0.018^{*}$ & $0.045^{*}$ & 0.645 & 0.107 \\
\hline \multicolumn{8}{|l|}{$C S^{e}$} \\
\hline$F$ & 0.505 & 0.010 & 45.700 & 2.410 & 0.040 & 0.006 & 0.246 \\
\hline d.f & 1,72 & 1,72 & 1,72 & 1,72 & 1,72 & 1,72 & 1,72 \\
\hline$P$ & 0.497 & 0.991 & $<0.001^{* *}$ & 0.122 & 0.935 & 0.992 & 0.674 \\
\hline \multicolumn{8}{|c|}{$\operatorname{cox}^{\mathrm{e}}$} \\
\hline$F$ & 1.920 & 2.122 & 16.849 & 3.872 & 1.027 & 0.361 & 0.406 \\
\hline d.f & 1,56 & 1,56 & 1,56 & 1,56 & 1,56 & 1,56 & 1,56 \\
\hline$P$ & 0.159 & 0.148 & $<0.001^{* *}$ & $0.044^{*}$ & 0.314 & 0.551 & 0.548 \\
\hline
\end{tabular}

Abbreviations: AMR, active metabolic rate, CS, citrate synthase; COX, cytochrome oxidase; MS, metabolic scope; LDH, lactate dehydrogenase; RMR, resting metabolic rate. ${ }^{a}$ Acclimation temperature.

bThyroid treatment.

'Test temperature.

${ }^{\mathrm{d}}$ Swimming performance.

${ }^{\mathrm{e}}$ Maximal activity.

${ }^{*} P<0.05$.

${ }^{*} P<0.01$.

between acclimation treatment and test temperature on the activity of LDH.

Paralleling responses of swimming performance and LDH activity, there were significant interactions between hypothyroid treatment and acclimation temperature for transcript levels of $\mathrm{PGC1} \alpha, \mathrm{COX} \mathrm{VB} 2$, COX II, ATPase A, ATPase B, and ATPase $8 / 6$ in muscle, whereby hypothyroid treatment significantly decreased transcript levels in cold-acclimated fish but had no effect on warm-acclimated fish (Figure 2E; Table 4; see Additional file 1: Table S1). There were significant effects of hypothyroid treatment on COX II and ATPase 8/6 in muscle and COXVB2 in liver (Figure 2E,F; Table 4; Table 5). Hypothyroid treatment had no significant effect on transcript levels of PGC1 $\beta$, PPAR $\delta, N R F 1$, and NRF2b in muscle, or on PGC1 $\alpha$, ATPase A, and ATPase B in liver (Figure 2E,F; Table 4; Table 5). For those genes that responded to acclimation treatments, there was a tendency for hypothyroid treatment to decrease transcript levels in cold-acclimated fish and increase transcript levels in warm-acclimated fish. 
Table 4 Two-way permutational multivariate analysis of variance (PERMANOVA) results comparing muscle mRNA levels between cold-acclimated and warm-acclimated normal thyroid and hypothyroid fish

\begin{tabular}{|c|c|c|c|c|c|c|c|c|c|}
\hline \multirow[b]{2}{*}{ Gene } & \multicolumn{3}{|c|}{ Acclimation temperature } & \multicolumn{3}{|c|}{ Thyroid status } & \multicolumn{3}{|c|}{ Acclimation temperature $\times$ Thyroid Status } \\
\hline & $F$ & d.f. & $P$ & $F$ & d.f. & $P$ & $F$ & d.f. & $P$ \\
\hline PGC1a & 3.330 & 1,34 & $0.041^{*}$ & 6.454 & 1,34 & $0.001^{* *}$ & 4.357 & 1,34 & $0.026^{*}$ \\
\hline PGC1 $\beta$ & 12.690 & 1,34 & $0.001^{* *}$ & 2.677 & 1,34 & 0.09 & 2.068 & 1,34 & 0.108 \\
\hline PPARS & 5.708 & 1,31 & $0.010^{*}$ & 0.172 & 1,31 & 0.827 & 2.511 & 1,31 & 0.117 \\
\hline NRF1 & 5.069 & 1,28 & $0.021^{*}$ & 0.921 & 1,28 & 0.343 & 0.268 & 1,28 & 0.714 \\
\hline NRF2a & 1.434 & 1,28 & 0.239 & 0.145 & 1,28 & 0.885 & 1.086 & 1,28 & 0.302 \\
\hline NRF2b & 4.108 & 1,17 & $0.045^{*}$ & 0.557 & 1,17 & 0.537 & 0.060 & 1,17 & 0.948 \\
\hline COX Vb2 & 1.996 & 1,33 & 0.124 & 3.786 & 1,33 & $0.029^{*}$ & 7.293 & 1,33 & $0.002^{* *}$ \\
\hline ATPase A & 3.612 & 1,27 & $0.048^{*}$ & 2.260 & 1,27 & 0.099 & 3.136 & 1,27 & $0.043^{*}$ \\
\hline ATPase B & 1.948 & 1,27 & 0.148 & 1.216 & 1,27 & 0.269 & 5.903 & 1,27 & $0.012^{*}$ \\
\hline $\operatorname{cox} \|$ & 12.410 & 1,25 & $0.001^{* *}$ & 3.850 & 1,25 & $0.026^{*}$ & 2.478 & 1,25 & 0.079 \\
\hline ATP 8/6 & 7.221 & 1,24 & $0.004^{* *}$ & 8.229 & 1,24 & $0.002^{* *}$ & 2.631 & 1,24 & 0.068 \\
\hline
\end{tabular}

Abbreviations: ATPase $A, F_{0} F_{1}$-ATPase subunit A; ATPase $B, F_{0} F_{1}$-ATPase subunit $B$; ATPase $8 / 6, F_{0} F_{1}$-ATPase subunits 8 and 6 ; COX II, Cytochrome $c$ oxidase subunit 2 ; COX Vb2, cytochrome $c$ oxidase subunit $5 b 2$; d.f. degrees of freedom; NRF1, Nuclear respiratory factor 1 ; NRF2a, Nuclear respiratory factor 2a; NRF2b, Nuclear respiratory factor $2 \mathrm{~b}$; PGC1a, Peroxisome proliferator-activated receptor $\gamma$ coactivator 1-a; PGC1 $\beta$, Peroxisome proliferator-activated receptor $\gamma$ coactivator 1- $\beta$; PPARS, Peroxisome proliferator-activated receptor $\delta a$ and $\delta b$.

${ }^{*} P<0.05$.

${ }^{*} P<0.01$.

The effects of hypothyroid treatment on response measures that did not acclimate

Hypothyroidism decreased resting metabolic rate at the $18^{\circ} \mathrm{C}$ test temperature, but increased resting metabolic rate at the $28^{\circ} \mathrm{C}$ test temperature (Figure 3A; Table 3). Hypothyroid treatment had no significant effect on CS activity or muscle transcript levels for NRF2a (Figure 3B,D; Table 3; Table 4). There was a significant interaction between hypothyroid treatment and maximal COX activity, whereby hypothyroidism significantly increased COX activity in muscle of the warm-acclimated fish but had no effect on the cold-acclimated fish (Figure 3c; see Table 3, Additional file 1: Table S1).

There were significant interactions between hypothyroid treatment and acclimation temperature for liver transcript levels of PGC1 $\beta$, PPAR $\delta$, NRF1, NRF2a, NRF2b, COX

Table 5 Two-way permutational multivariate analysis of variance (PERMANOVA) results comparing liver mRNA levels between cold-acclimated and warm-acclimated normal thyroid and hypothyroid fish

\begin{tabular}{|c|c|c|c|c|c|c|c|c|c|}
\hline \multirow[b]{2}{*}{ Gene } & \multicolumn{3}{|c|}{ Acclimation temperature } & \multicolumn{3}{|c|}{ Thyroid status } & \multicolumn{3}{|c|}{ Acclimation temperature $\times$ thyroid status } \\
\hline & $F$ & d.f. & $P$ & $F$ & d.f. & $P$ & $F$ & d.f. & $P$ \\
\hline PGC1a & 13.672 & 1,32 & $0.001^{* *}$ & 2.597 & 1,32 & 0.095 & 1.521 & 1,32 & 0.238 \\
\hline PGC1 $\beta$ & 26.692 & 1,29 & $0.001^{* *}$ & 1.191 & 1,29 & 0.274 & 6.374 & 1,29 & $0.011^{*}$ \\
\hline PPARS & 25.657 & 1,31 & $0.001^{* *}$ & 1.128 & 1,31 & 0.324 & 6.139 & 1,31 & $0.010^{*}$ \\
\hline NRF1 & 32.817 & 1,26 & $0.001^{* *}$ & 0.784 & 1,26 & 0.400 & 3.464 & 1,26 & $0.050^{*}$ \\
\hline NRF2a & 7.869 & 1,22 & $0.004^{* *}$ & 1.163 & 1,22 & 0.290 & 5.015 & 1,22 & $0.020^{*}$ \\
\hline NRF2b & 15.085 & 1,24 & $0.001^{* *}$ & 0.578 & 1,24 & 0.497 & 6.708 & 1,24 & $0.017^{*}$ \\
\hline COX Vb2 & 9.789 & 1,20 & $0.005^{* *}$ & 3.490 & 1,20 & $0.049^{*}$ & 0.336 & 1,20 & 0.672 \\
\hline ATPase A & 23.119 & 1,32 & $0.001^{* *}$ & 0.292 & 1,32 & 0.713 & 1.109 & 1,32 & 0.308 \\
\hline ATPase B & 6.456 & 1,33 & $0.007^{* *}$ & 0.097 & 1,33 & 0.942 & 1.604 & 1,33 & 0.189 \\
\hline $\operatorname{cox} \|$ & 6.458 & 1,22 & $0.007^{* *}$ & 1.240 & 1,22 & 0.295 & 6.377 & 1,22 & $0.013^{*}$ \\
\hline ATP 8/6 & 4.056 & 1,21 & 0.06 & 0.422 & 1,21 & 0.571 & 3.904 & 1,21 & $0.044^{*}$ \\
\hline
\end{tabular}

Abbreviations: ATPase $A, F_{0} F_{1}$-ATPase subunit A; ATPase $B, F_{0} F_{1}$-ATPase subunit $B$; ATPase $8 / 6, F_{0} F_{1}$-ATPase subunits 8 and 6 ; COX II, Cytochrome $c$ oxidase subunit 2; COX Vb2, Cytochrome c oxidase subunit 5b2; d.f. degrees of freedom; NRF1, Nuclear respiratory factor 1; NRF2a, Nuclear respiratory factor 2a; NRF2b, Nuclear respiratory factor $2 b$; PGC1a, Peroxisome proliferator-activated receptor $\gamma$ coactivator 1 - $\alpha$; PGC1 $\beta$, Peroxisome proliferator-activated receptor $\gamma$ coactivator $1-\beta$; PPAR $\delta$, Peroxisome proliferator-activated receptor $\delta a$ and $\delta b$. ${ }^{*} P<0.05$.

${ }^{*} P<0.01$. 


\section{A. Ucrit}

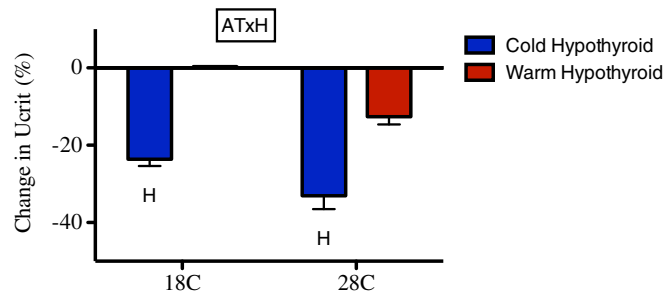

C. Metabolic Scope

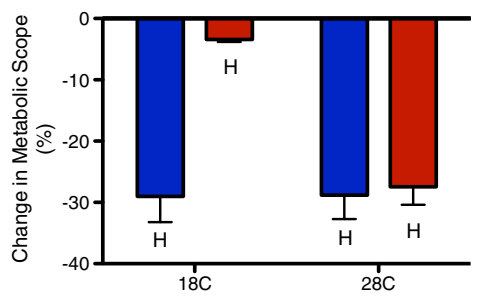

\section{E. Muscle mRNA}

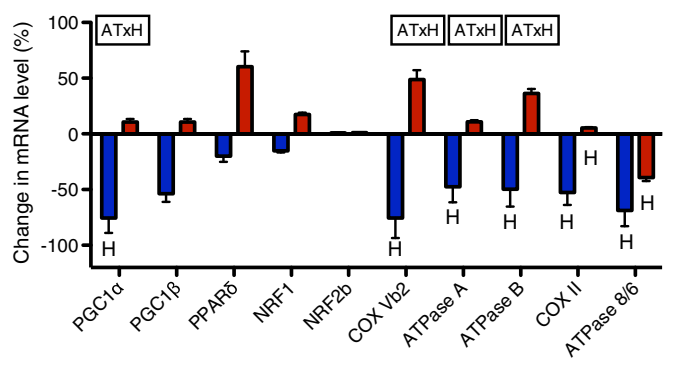

\section{F. Liver mRNA}

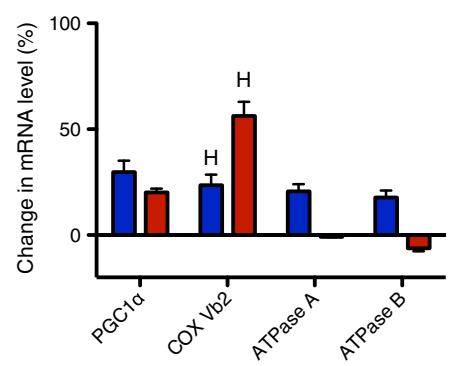

\section{B. Active $\mathrm{MO}_{2}$}

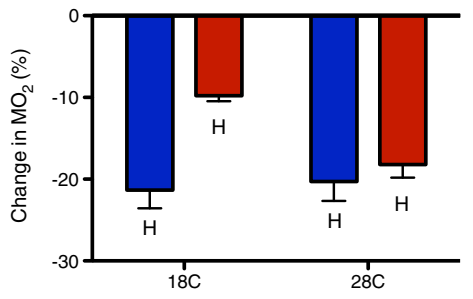

D. LDH Activity

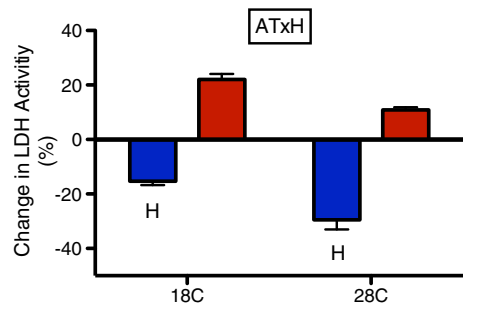

Figure 2 Effects of hypothyroid treatment on cold-acclimation responses. Percentage difference in $(\mathbf{A}) U_{\text {crit, }}(\mathbf{B})$ active metabolic rate, (C) metabolic scope, (D) maximal lactate dehydrogenase (LDH) activity, (E) muscle mRNA transcript levels and (F) liver mRNA transcript levels in cold-acclimated and warm-acclimated hypothyroid fish (blue and red, respectively) relative to normal thyroid fish. $\mathrm{H}$, significant effect of hypothyroid treatment; AT $\times \mathrm{H}$, significant interaction between acclimation temperature and hypothyroid treatment.

VB2, COX II, and ATPase 8/6, whereby hypothyroidism significantly increased the transcript levels of PGC1 $\beta$, PPARS, NRF1, NRF2a, and NRF2b in cold-acclimated fish and significantly reduced transcript levels of PGC1 $\beta$ and COX II in warm-acclimated fish (Figure 3D; Table 5; see Additional file 1: Table S1). Overall, for those genes that did not respond to acclimation treatments, there was a tendency for hypothyroidism to increase transcript levels in cold-acclimated fish and decrease transcript levels in warm-acclimated fish. This trend was the reverse of the pattern seen in the genes that did respond to thermal acclimation in muscle. 


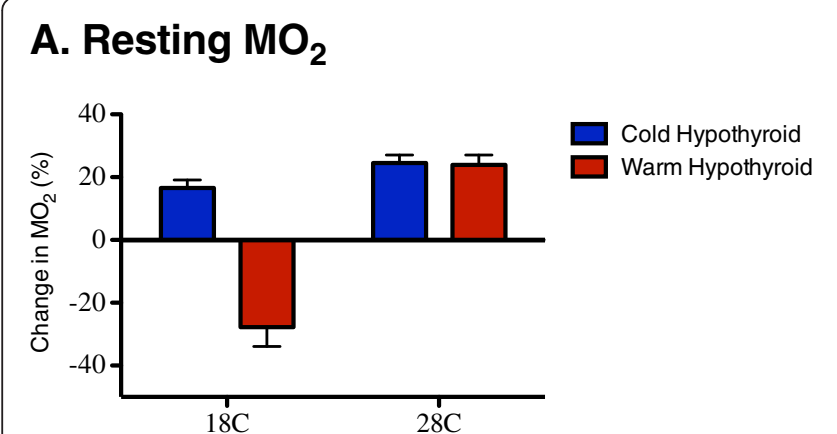

\section{C. coX Activity}

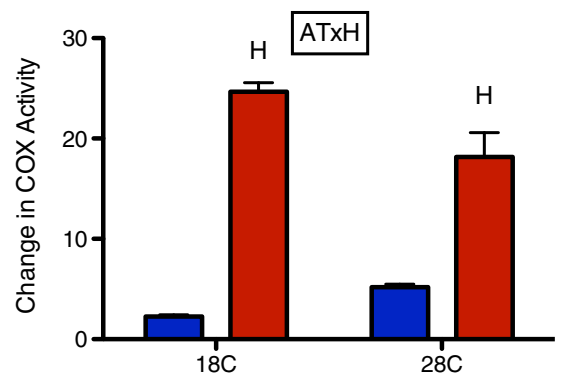

B. CS Activity

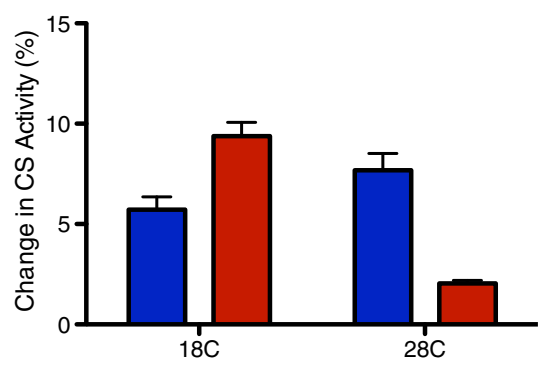

\section{Muscle and Liver mRNA}

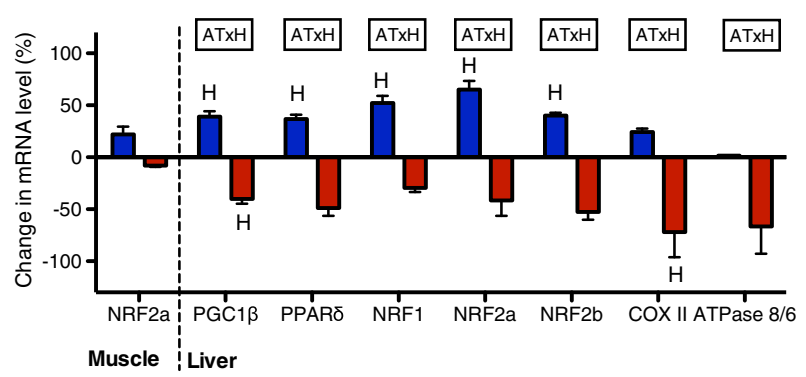

Figure 3 Effects of hypothyroid treatment on measures that do not acclimate to cold. Percentage difference in (A) resting metabolic rate, (B) maximal citrate synthase (CS) activity, (C) maximal cytochrome c oxidase (COX) activity, and (D) muscle and liver mRNA transcript levels in cold-acclimated and warm-acclimated hypothyroid fish (blue and red, respectively) relative to normal thyroid fish; $\mathrm{H}$. significant effect of hypothyroid treatment; AT $\times \mathrm{H}$, significant interaction between acclimation temperature and hypothyroid treatment.

The effects of $T_{2}$ and $T_{3}$ supplementation for responses sensitive to hypothyroid treatment

Supplementation of hypothyroid fish with either $\mathrm{T}_{2}$ or $\mathrm{T}_{3}$ resulted in a significant recovery of sustained swimming performance in cold-acclimated fish at both the $18^{\circ} \mathrm{C}$ and $28^{\circ} \mathrm{C}$ test temperatures (Figure 4A; Table 6). There was no significant effect of $\mathrm{T}_{2}$ or $\mathrm{T}_{3}$ supplementation on resting metabolic rate, but $\mathrm{T}_{2}$ supplementation significantly restored active metabolic rate and metabolic scope at both test temperatures (Figure 4B,C; Table 4). There was a significant effect of $T_{2}$ and $T_{3}$ supplementation on muscle LDH activity, with $\mathrm{T}_{2}$ tending to decrease activity levels, and $\mathrm{T}_{3}$ increasing activity levels (Figure 4D; Table 6). In muscle, $\mathrm{T}_{2}$ supplementation resulted in a significant recovery of transcript levels for PGC1 $\alpha$ and COX VB2, whereas $\mathrm{T}_{3}$ supplementation resulted in a significant recovery of transcript levels for PGC1 $\alpha$, COX VB2, ATPase B, COX II and ATPase 8/6 (Figure 4F; Table 7). In liver, $\mathrm{T}_{2}$ or $\mathrm{T}_{3}$ supplementation had no significant effect on the transcript levels of any of the genes previously shown to be sensitive to hypothyroid treatment (Figure 4G; Table 7).

\section{Discussion}

We have shown that $\mathrm{TH}$ regulates thermal acclimation of metabolism in an ectothermic vertebrate. Our principal novel findings were that 1) the actions of $\mathrm{TH}$ are temperature-specific, and 2) $\mathrm{TH}$ regulates thermal acclimation in ectotherms. We also showed that 3) $\mathrm{T}_{2}$ has a functional role in this thermal response, which, to our knowledge has not been shown in any other system. Thus, to our knowledge, this is the first time that an environmental factor as pervasive as temperature has been shown to determine not just the magnitude of a hormonemediated response, but also the direction.

The traditional model for hormonal regulation is based on homeostatic control [24], by which the bioavailability of a hormone is adjusted to regulate its action. Opposing responses are typically mediated by antagonistic hormone pairs [37], but single hormones can also drive different responses depending upon the physiological context [24]. In the current study, we identified a novel signaling response, by which $\mathrm{TH}$ elicits a positive or negative response depending on the actual temperature and thermal history of the animal. TH has long been known to act in a tissue-specific manner [38,39], and it is possible that the same mechanisms that underlie its tissue specificity also underlie its temperature specificity. Phenotypic differences between tissues are primarily driven by differential patterns in gene expression defined during ontogeny $[40,41]$, but gene-expression patterns, and therefore tissue phenotypes, are plastic, and can be 
A. Ucrit

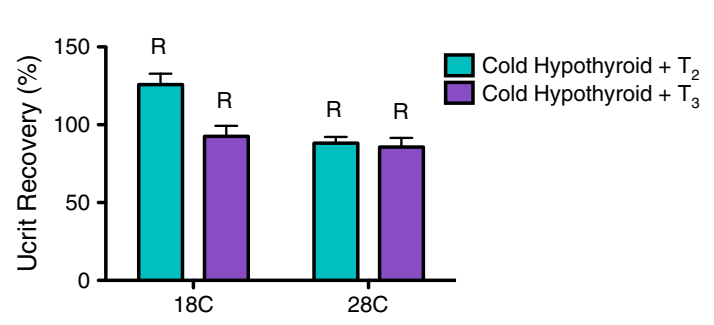

C. Active $\mathrm{MO}_{2}$

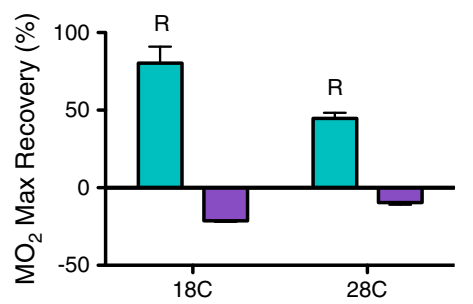

E. LDH Activity

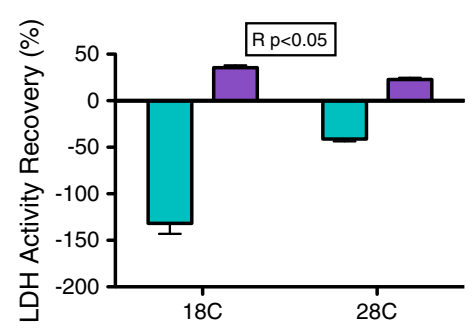

B. Resting $\mathrm{MO}_{2}$

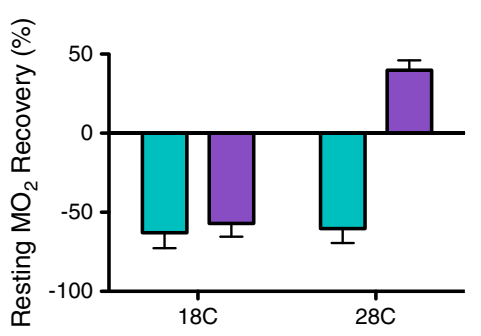

D. Metabolic Scope

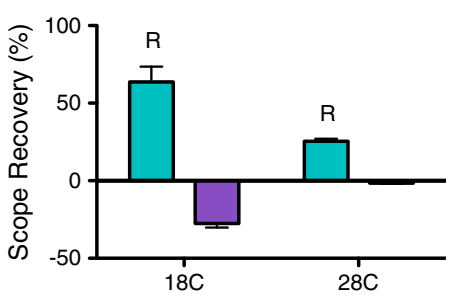

F. Muscle mRNA

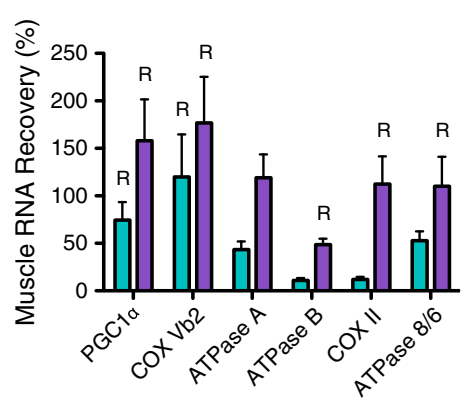

\section{G. Liver mRNA}

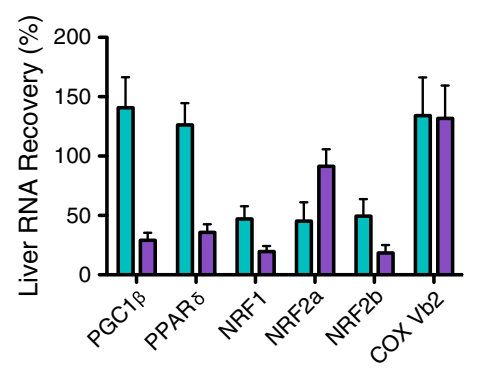

Figure 4 Effects of $T_{2}$ and $T_{3}$ supplementation on thyroid hormone (TH)-sensitive measures in cold-acclimated fish. Percentage recovery in $(\mathbf{A}) U_{\text {crit, }}$ (B) resting metabolic rate, $(\mathbf{C})$ active metabolic rate, (D) metabolic scope, (E) muscle LDH activity, (F) muscle mRNA transcript levels and (G) liver mRNA transcript levels in cold-acclimated hypothyroid fish supplemented with either $T_{2}$ (teal) or $T_{3}$ (purple); $R$, significant recovery with supplementation treatment; $R P<0.05$, significant effect of ANOVA where post hoc analyses were not significant.

adjusted in response to environmental factors such as temperature [1-3]. Thus, the thermal-acclimation response may change the tissue phenotype temporally to alter sensitivity to $\mathrm{TH}$ in a way that may parallel how different tissue types respond to $\mathrm{TH}$.

The temperature specificity of $\mathrm{TH}$ action is evident at multiple levels of physiological organization, and mediates performance functions that determine fitness. We have shown that $\mathrm{TH}$ regulates energy metabolism and locomotor performance in response to chronic exposure to cold. This is the first time, to our knowledge, that a central regulator of thermal acclimation has been identified in an ectotherm, and provides a model that could explain vertebrate radiation during thermal-niche expansion. TH 
Table 6 Two-way ANOVA results comparing parameters between cold-acclimated normal thryoid, hypothyroid, and $\mathbf{T}_{2^{-}}$or $\mathbf{T}_{3^{-}}$supplemented fish ${ }^{\mathrm{a}}$

\begin{tabular}{|c|c|c|c|c|c|c|c|c|c|}
\hline & \multicolumn{3}{|c|}{ Thyroid status } & \multicolumn{3}{|c|}{ Test temperature } & \multicolumn{3}{|c|}{ Thyroid status $\times$ test temperature } \\
\hline & $\bar{F}$ & d.f. & $P$ & $\underline{F}$ & d.f. & $P$ & $F$ & d.f. & $P$ \\
\hline $\mathrm{U}_{\text {crit }}^{\mathrm{b}}$ & 12.689 & 3,65 & $0.001^{* *}$ & 31.085 & 1,65 & $0.001^{* *}$ & 0.959 & 3,65 & 0.417 \\
\hline RMR & 1.466 & 3,55 & 0.234 & 4.253 & 1,55 & $0.044^{*}$ & 0.209 & 3,55 & 0.890 \\
\hline AMR & 3.535 & 3,55 & $0.020^{*}$ & 11.032 & 1,55 & $0.002^{* *}$ & 0.050 & 3,55 & 0.985 \\
\hline Scope & 3.170 & 3,55 & $0.006^{* *}$ & 50.558 & 1,55 & $0.005^{* *}$ & 0.132 & 3,55 & 0.899 \\
\hline $\mathrm{LDH}^{\mathrm{C}}$ & 11.025 & 3,64 & $0.001^{* *}$ & 130.539 & 1,64 & $0.001^{* *}$ & 0.516 & 3,64 & 0.673 \\
\hline
\end{tabular}

Abbreviations: AMR, active metabolic rate; d.f., degrees of freedom; MS, metabolic scope; LDH, lactate dehydrogenase; RMR, resting metabolic rate. ${ }^{a}$ Citrate synthase was not measured because there was no significant effect of thyroid hormone in the cold-acclimated and warm-acclimated normal thyroid and hypothyroid fish.

${ }^{b}$ Swimming performance.

${ }^{\mathrm{C}}$ Maximal activity.

${ }^{*} P<0.05$.

${ }^{*} P<0.01$.

appears to have evolved as an environmental signaling molecule prior to vertebrate evolution [26-30,42,43]. In many invertebrates, $\mathrm{TH}$ suppresses larval structures, and promotes the growth and development of the juvenile rudiment [28]. Although many of these animals require exogenous THs ingested from food, others can synthesize

Table 7 One-way ANOVA results comparing muscle and liver mRNA levels between cold-acclimated normal thyroid, hypothyroid, and $\mathrm{T}_{2}$-supplemented or $\mathrm{T}_{3}$-supplemented fish ${ }^{\mathrm{a}}$

\begin{tabular}{|c|c|c|c|c|c|c|}
\hline \multirow[b]{2}{*}{ Gene } & \multicolumn{3}{|l|}{ Muscle } & \multicolumn{3}{|l|}{ Liver } \\
\hline & $F$ & d.f. & $P$ & $\bar{F}$ & d.f. & $P$ \\
\hline PGC1a & 10.233 & 3,25 & $<0.001^{* *}$ & 1.791 & 3,39 & 0.165 \\
\hline$P G C 1 \beta$ & & & & 2.202 & 3,34 & 0.106 \\
\hline PPAR $\delta$ & & & & 1.202 & 3,38 & 0.322 \\
\hline NRF1 & & & & 0.731 & 3,29 & 0.542 \\
\hline NRF2a & & & & 1.272 & 3,21 & 0.310 \\
\hline NRF2b & & & & 0.714 & 3,23 & 0.554 \\
\hline Cox Vb2 & 6.858 & 3,28 & $0.001^{* *}$ & 2.440 & 3,21 & 0.093 \\
\hline ATPase A & 2.422 & 3,30 & 0.085 & & & \\
\hline ATPase B & 3.380 & 3,29 & $0.032^{*}$ & & & \\
\hline $\operatorname{cox} \|$ & 3.705 & 3,23 & $0.026^{*}$ & & & \\
\hline ATP 8/6 & 5.530 & 3,29 & $0.004^{* *}$ & & & \\
\hline
\end{tabular}

Abbreviations: ATPase $A, F_{0} F_{1}$-ATPase subunit $A$; ATPase $B, F_{0} F_{1}$-ATPase subunit $B$; ATPase $8 / 6, F_{0} F_{1}$-ATPase subunits 8 and 6 ; COX II, Cytochrome $C$ oxidase subunit 2; $\mathrm{COX} \mathrm{Vb2,} \mathrm{Cytochrome} \mathrm{c} \mathrm{oxidase} \mathrm{subunit} \mathrm{5b2;} \mathrm{d.f.} \mathrm{degrees} \mathrm{of}$ freedom; NRF1, Nuclear respiratory factor 1; NRF2a, Nuclear respiratory factor 2a; NRF2b, Nuclear respiratory factor 2b; PGC1a, Peroxisome proliferatoractivated receptor $\gamma$ coactivator $1-\alpha ; P G C 1 \beta$, Peroxisome proliferator-activated receptor $\gamma$ coactivator $1-\beta$; PPAR $\delta$, Peroxisome proliferator-activated receptor $\delta a$ and $\delta b$.

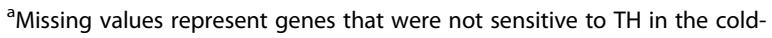
acclimated and warm-acclimated normal thyroid and hypothyroid fish, and therefore were not analyzed in cold-acclimated normal thyroid, hypothyroid, and $T_{2}$-supplemented or $T_{3}$-supplemented fish.

${ }^{*} P<0.05$.

${ }^{*} P<0.01$.
THs or TH-like compounds endogenously [25,32,44-46]. It is interesting to note that in echinoderms, endogenously synthesized TH has been suggested to be a derived trait [25]. Growth and developmental rates are intrinsically linked to energy metabolism, and it is therefore likely that $\mathrm{TH}$ has always regulated these processes, at least in part by regulating metabolism. It is unknown whether the temperature specificity of $\mathrm{TH}$ is conserved in invertebrates, but it is conceivable that $\mathrm{TH}$ pathways evolved their sensitivity to temperature because both play such major roles in development [47-49]. If $\mathrm{TH}$ regulated metabolism to promote development at thermally challenging temperatures, then selection could favor this additional role. With an endogenous store of $\mathrm{TH}$ in the form of the thyroid gland, vertebrates could regulate these responses autonomously, and exploit novel thermal environments while maintaining important performance parameters such as locomotor capacity.

The properties that underlie the role of $\mathrm{TH}$ in thermal acclimation, temperature sensitivity, and metabolic control may have predisposed this hormone for a regulatory role in the evolution of endothermy. Of the response variables related to cold acclimation that we measured, most were highly sensitive to $\mathrm{TH}$. The genes that were upregulated by TH during cold acclimation in zebrafish are homologous to those that control mammalian thermogenesis. In mammals, $\mathrm{TH}$ modulates the transcriptional regulation of metabolism by controlling expression levels of PGC1 $\alpha$ [50], which plays a master role in coordinating the cross-genome expression of transcription factors involved in mitochondrial biogenesis and proteins that drive oxidative metabolism, including $\mathrm{COX}$ and $\mathrm{F}_{0} \mathrm{~F}_{1^{-}}$ ATPase [51]. Our findings show that this same pathway underlies cold acclimation in an ectotherm. The most parsimonious explanation is that these pathways were conserved in early vertebrate ancestors; however, without 
similar analyses of other ectotherms, we cannot preclude the possibility that they were independently derived in both fish and mammals. PGC1 $\alpha$ has also been shown to adjust skeletal muscle phenotype in ways that affect locomotion [52]. As is the case in mammals, PGC1 $\alpha$ appears to be conserved as a target of $\mathrm{TH}$ in zebrafish, and probably also in other ectotherms. With the same pathways underlying both processes, the evolution of thermogenesis in mammals and birds [53-57] may have already been preprogrammed as a component of the cold-acclimation response in ectotherms.

$\mathrm{T}_{3}$ is often considered to be the only $\mathrm{TH}$ capable of genomic action because of its unique affinity for thyroid receptors [23]. However, $\mathrm{T}_{2}$ has recently been shown to stimulate metabolism in mammals and fish [23]. Our work supports the notion that $\mathrm{T}_{2}$ is also an important transcriptional regulator [58,59]. In many cases, $T_{2}$ was just as effective as, if not more effective than, $\mathrm{T}_{3}$ at regulating the transcription of metabolic genes. Although $\mathrm{T}_{2}$ has poor affinity for thyroid receptors, it could exert its transcriptional control through cell surface receptors that are also known to respond to $\mathrm{TH}[5,18,60]$, or through reversible epigenetic modifications to histone complexes [61]. Importantly, the current study shows that $T_{2}$ modulates performance parameters in the whole animal, which means that it is of ecological relevance and probably also of medical relevance. TH is associated with many modern lifestyle-induced conditions, and zebrafish have emerged as an important model for human endocrine diseases including obesity, diabetes, and metabolic syndromes $[35,36]$. The fact that $\mathrm{T}_{2}$ regulates metabolism and locomotor performance in a manner that is potentially very different from that of $T_{3}$ means that the mechanistic basis of $\mathrm{TH}$ action is far broader than realized to date. A corollary is that thyroid-related diseases may be more complex, but also that there may be novel avenues for treatments that specifically target $T_{2}$.

Several studies have measured changes in $T_{3}$ and $T_{4}$ plasma levels during thermal response in fish, but the combined results are ambiguous. In the current study we found a high level of variation in $\mathrm{T}_{3}$ levels in warmacclimated euthyroid fish. There was also much variation in the TH levels of the fish receiving $T_{2}$ and $T_{3}$ supplement treatments, although all individuals measured had supplementation levels greater than or equal to their euthyroid counterparts. Overall, the muscle-specific concentrations of $T_{3}$ and $T_{2}$ in our study decreased drastically with cold acclimation, when their effects were most pronounced. However, TH concentrations alone do not indicate the bioavailability and/or bioactivity of the hormone within the target tissue. Instead, the action of $\mathrm{TH}$ is modulated by downstream regulators, which include plasma distributor proteins, TH transporters, deiodinase enzymes, intracellular reservoir proteins, target proteins (thyroid receptors, cell surface receptors, and specific enzymes), and transcriptional regulators [16-21,62]. The actions of $\mathrm{TH}$ may be more sensitive to changes in these downstream regulatory elements than to absolute free TH levels.

In many cases, the warm-acclimated zebrafish were far less sensitive to $\mathrm{TH}$ than cold-acclimated fish. This was especially evident in measures of locomotor performance. Decreased responsiveness to $\mathrm{TH}$ at warmer temperatures suggests that chronic increases in temperature, such as those brought about by global warming, will reduce the capacity of animals to adjust to environmental variation. Chronic warming could conceivably alter tissue phenotypes in ways that dampen, or reverse, THmediated response. This would interfere with $\mathrm{TH}$ as an environmental signaling molecule, and would compromise its crucial role in ectotherm growth and development. Importantly, many aquatic pollutants found worldwide, such as dioxins, bisphenol A, and phthalates, are thyroiddisrupting chemicals (TDCs) and bioaccumulate higher up the food chain [63]. Our findings indicate that the toxic effects of these chemicals may be temperature-specific, which is of crucial importance to the ecological influence of these pollutants. Together, climate change and rising levels of global pollution may amplify these risks. Warming temperatures are likely to result in higher concentrations, longer durations, and increased distributions of TDCs throughout the water column [64].

\section{Conclusions}

Our finding that the effects of TH can depend upon the thermal history of an animal means that the toxicities of thyroid-disrupting pollutants, levels of which are increasing on a global basis, may vary with temperature. A corollary of this is that toxicological assessments of TDCs should consider the natural range of temperatures that a species experiences, or is predicted to experience in future. We show that $\mathrm{TH}$ is an important regulator of thermal acclimation in an ectotherm, which gives a new perspective on the evolution of thermal plasticity because it would be closely tied to the evolutionary history of the thyroid system. It is not known whether the role of $\mathrm{TH}$ in mediating thermal responses is conserved evolutionarily, or whether it is derived independently in mammals and earlier vertebrates. Based on our findings, we propose that the role of $\mathrm{TH}$ in thermal acclimation of fish predisposed it to evolve for regulatory control of thermogenesis. Decades of TH research have focused almost exclusively on $\mathrm{T}_{3}$, but the current study shows that that $\mathrm{T}_{2}$ also stimulates physiological activities that are of biological importance. Little is known about $\mathrm{T}_{2}$ signaling mechanisms, but the fact that it influences whole-animal performance independently from $\mathrm{T}_{3}$ suggests that it is important in both ecological and medical contexts. 


\section{Methods}

\section{Ethics statement}

All experiments were carried out with the approval of the University of Sydney Animal Experimentation Ethics Committee (approval number L04/6-2010/2/5325).

\section{Animals and treatments}

Zebrafish were purchased from commercial suppliers (Kim's Aquatic World, Sydney, NSW, Australia, and Livefish, Bundaberg, QLD, Australia) and maintained at $23^{\circ} \mathrm{C}$ in 10 -liter tanks of dechlorinated water at densities between 1.5 and 2 fish/l for at least 1 week before the start of the treatment regimens. Fish were fed ad libitum and maintained in a 14-hour light/10-hour dark photoperiod.

Fish were split into two temperature treatments, a cold acclimation group kept at $18^{\circ} \mathrm{C}$, and a warm acclimation group at $28^{\circ} \mathrm{C}$, and held at these temperatures $\left( \pm 0.5^{\circ} \mathrm{C}\right)$ for 3 weeks. Within these acclimation groups, fish were separated into a normal thyroid group and a hypothyroid treatment group. Within the cold-acclimated hypothyroid group, fish were further divided into three treatment groups to be given daily supplements of $\mathrm{T}_{3}$ (3,5,3'-triiodothyronine; Sigma), $\mathrm{T}_{2}$ (3,5-diiodothyronine; Sigma), or the ethanol vehicle. There were five replicate tanks per treatment.

We induced hypothyroidism by maintaining the tank water with $0.3 \mathrm{mmol} / \mathrm{l}$ propylthiouracil (PTU; Sigma, Australia), which blocks the production of $\mathrm{T}_{4}$ at the thyroid gland [23], dissolved in a DMSO vehicle. Every 4 days, $80 \%$ of the tank water was changed, and the PTU was added again to return the concentration to $0.3 \mathrm{mmol} / \mathrm{l}$. The hypothyroid groups were also treated with $5 \mu \mathrm{mol} / \mathrm{l}$ iopanoic acid (Thermofisher Scientific Inc., Australia) daily to inhibit deiodinase activity, thereby preventing the peripheral metabolism of TH. Tanks holding the normal thyroid groups were maintained with proportionate amounts of the respective vehicles $(0.05 \%$ DMSO and $0.025 \%$ ethanol).

\section{Sustained swim performance}

Sustained swim performance (critical sustained swim speed, $U_{\text {crit }}$ [65]) was measured in a flume consisting of a clear Perspex tube $150 \mathrm{~mm}$ in length and $26 \mathrm{~mm}$ in diameter, tightly fitted into the single exit of a Y-shaped rubber connector (total length 0.15 meters). Two $12 \mathrm{~V}$ inline submersible pumps (iL500; Rule, Miami, FL, USA) were fitted into the other openings of the Y connector. A plastic grid separated the flume from the two pumps, and bundles of hollow straws were positioned at each end of the flume to promote laminar flow. The flume and pumps were submerged in a plastic tank $(645 \times 423 \times$ $276 \mathrm{~mm}$ ). We used a variable DC power source (MP3090;
Powertech, Osborne Park, WA, Australia) to adjust the flow speed, which was calibrated using a flow meter (FP101; Global Water, Gold River, CA, USA). U crit $_{\text {was de- }}$ termined in accordance with published protocols $[65,66]$, with a time interval between speed increments of $600 \mathrm{sec}-$ onds, a speed increment of 0.06 meters and an initial flow rate of $0.2 \mathrm{~m} / \mathrm{s}$. Fish were allowed 15 minutes to equilibrate to the flume conditions before swim trials were begun. Animals were swum until fatigued, which was defined as the time when fish could no longer hold their position in the water column [65]. Each fish was swum at $18^{\circ} \mathrm{C}$ and $28^{\circ} \mathrm{C}$ in random order, with at least 24 hours between swim trials. $U_{\text {crit }}$ is reported as body length (BL) per second (s).

\section{Metabolic scope}

Resting and maximum rates of $\mathrm{O}_{2}$ consumption were analyzed with a fiber optic oxygen sensor (Microx 1/ FIBOX; PreSens, Regensburg, Germany) in custommade metabolic chambers (circular sealable plastic containers of $90 \mathrm{ml}$ volume) at $18^{\circ} \mathrm{C}$ and $28^{\circ} \mathrm{C}$. For resting rates of $\mathrm{O}_{2}$ consumption, fish were placed inside dark sealed chambers continuously supplied with oxygenated water via input tubes for at least 60 minutes before trials began, to allow them to equilibrate. Preliminary measures of metabolic rate over 24 hours in the same setup showed that the zebrafish reached resting status within 60 minutes. After the equilibration period, the flow of oxygenated water was stopped, and the tubes servicing each chamber were sealed via plastic valves to ensure a closed system. An initial $\left[\mathrm{O}_{2}\right]$ reading was taken, followed by a final $\left[\mathrm{O}_{2}\right]$ reading after 20 minutes. The total $\mathrm{O}_{2}$ depletion over this period was used to calculate the mass-specific resting metabolic rate. To measure the maximum rate of $\mathrm{O}_{2}$ consumption, a magnetic stir bar was added into the same chamber and partitioned from the bottom portion with a wire mesh. The chamber was placed on a magnetic stirring plate and stirring intensity was used to manipulate flow speed. A plastic column was placed vertically in the center of the chamber to reduce turbulence. To ensure active status was reached, fish were swum for 2 minutes before the initial $\left[\mathrm{O}_{2}\right]$ was measured. Final $\left[\mathrm{O}_{2}\right]$ was measured at 7 minutes. The total $\mathrm{O}_{2}$ depletion over 5 minutes was used to calculate mass-specific active metabolic rate. Fish were monitored for the full 7-minute trial, and water flow was adjusted so that the fish were swum at maximum capacity, which was defined as when the fish visibly struggled to hold their position in the water column. Oxygen concentration was also measured in empty metabolic chambers at both test temperatures to control for alternative sources of oxygen depletion. Rate of oxygen consumption was calculated using the formula 


$$
\left(\left(\mathrm{C}_{2}-\mathrm{C}_{1}\right) \times \mathrm{V}\right) /(\mathrm{M} \times \mathrm{T}),
$$

where $\mathrm{C}_{1}$ is the initial concentration of $\mathrm{O}_{2}, \mathrm{C}_{2}$ is the final concentration of $\mathrm{O}_{2}, \mathrm{~V}$ is the volume of the chamber, $\mathrm{M}$ is the mass of the fish and $\mathrm{T}$ is the trial time. Metabolic scope was calculated as the difference between active and resting metabolic rates.

\section{Thyroid hormone quantification}

Unfortunately, the limits of detection did not allow us to analyze the fish liver tissue because of its small size. Levels of $T_{3}$ and $T_{2}$ (Table 3, Table 4) were quantified in muscle tissue as described previously $[67,68]$, and expressed as means, and as ranges of the mean in cases where the TH metabolite was detected in amounts below the limits of quantification.

\section{Enzyme assays}

We measured the activities of LDH, CS and COX to assess how acclimation temperature and thyroid status affect maximal rates of metabolic enzymes. We chose these enzymes because they are important components of glycolytic and oxidative metabolism [69,70]. Tail muscle was collected, transferred into liquid nitrogen, and stored at $-80^{\circ} \mathrm{C}$ for later analysis. Enzyme activities were determined in accordance with published protocols [71].

\section{mRNA concentrations}

Upon completion of treatments, the zebrafish were euthanized by immersion in a buffered MS222 (tricaine methane sulfonate) solution $(0.4 \mathrm{~g} / \mathrm{l} \mathrm{MS} 222+0.8 \mathrm{~g} / \mathrm{l}$ $\mathrm{Na}_{2} \mathrm{HCO}_{3}$ ). Liver and muscle were dissected and stored in RNAlater (Ambion, USA) at $-20^{\circ} \mathrm{C}$. RNA was extracted from samples (TRIreagent; Molecular Research Center, Cincinnati, OH, USA), in accordance with the manufacturer's instructions. RNA concentration and quality were verified using a spectrophotometer (NanoDrop Technologies, Australia) and a microfluidics-based platform (Bioanalyzer 2100; Agilent Tecnologies, Australia) when necessary. An aliquot $(2 \mu \mathrm{g})$ of total RNA from each sample was treated with DNAse I (Sigma-Aldrich) and reverse-transcribed using RNAse HMMLV reverse transcriptase (Bioscript; Bioline, Australia) and random hexamer primers (Bioline).

Quantitative reverse transcriptase (qRT)-PCR was performed on a qRT-PCR machine ( 7500; Applied Biosystems, Foster City, CA, USA) in accordance with published protocols [66]. Primers for important transcriptional regulators of metabolic enzymes, peroxisome proliferator-activated receptor $\gamma$ coactivators $1-\alpha$ and $1-\beta$ (PGC1 $\alpha$ and PGC1 $\beta$ ), peroxisome proliferator-activated receptors $\delta \mathrm{a}$ and $\delta \mathrm{b}(\mathrm{PPAR} \delta)$, nuclear respiratory factors $1,2 a$ and $2 b$ (NRF1, NRF2a and NRF2b), and subunits of metabolic enzymes, cytochrome c oxidase subunits VB2 and II (COX VB2 and COX II), and $\mathrm{F}_{0} \mathrm{~F}_{1}$-ATPase subunits A, B, 8 and 6 (ATPase A, ATPase B and ATPase 8/6) were adopted from published works, or designed from their respective Genbank sequences (see Additional file 2: Table S2). The gene transcripts were chosen because they encode enzymes, enzyme subunits, transcription factors, and coactivators that are important regulators of oxidative phosphorylation [3,70,72]. All qPCRs were run in 96-well optical plates (BIOplastics, Landgraaf, the Netherlands). Real-time PCR reactions contained $1 \times$ SensiMix SYBR (Bioline, Australia), $4.5 \mathrm{mmol} / \mathrm{l} \mathrm{MgCl}_{2}, 50$ to $900 \mathrm{nmol} / \mathrm{l}$ of each primer and approximately $100 \mathrm{ng}$ cDNA. The cycle consisted of $95^{\circ} \mathrm{C}$ for 7 minutes, followed by 40 cycles of $95^{\circ} \mathrm{C}$ for 20 seconds and $58^{\circ} \mathrm{C}$ for 1 minute. Dissociation-curve analysis was performed after the amplification step to verify the presence of only a single PCR product. Transcript expression levels of the 11 target genes in each treatment group were normalized to elongation factor 1 (EF1)- $\alpha$ in accordance with recent recommendations for zebrafish housekeeping genes [73], and were expressed relative to the warm-acclimated normal thyroid treatment for the warm/cold hypothyroid experiment, and to the cold-acclimated normal thyroid treatment for the $T_{3} / T_{2}$ supplementation experiment.

\section{Statistical analyses}

Data are presented as means \pm standard error of the mean (SEM) Trifactorial datasets (acclimation temperature $\times$ thyroid status $\times$ test temperature) and bifactorial datasets for mRNA analysis (acclimation temperature $x$ thyroid status) were analyzed by permutational multivariate analysis of variance (PERMANOVA) using the Primer 6 and PERMANOVA+ packages (PRIMER-E Ltd, Plymouth, Cornwall UK). In the case of interactions involving acclimation temperature and test temperature, a priori planned contrasts were conducted in PERMANOVA to determine the main effects of acclimation temperature in the normal thyroid treatments, and of thyroid status in the cold and warm acclimation treatments. The remaining bifactorial datasets (thyroid status $\times$ test temperature) and single-factor datasets (thyroid status) were analyzed by ANOVA followed by Tukey post hoc tests using PASW Statistics 18. Where ANOVA was used, all data were tested for normality and homogeneity of variance using Levene's test. If a dataset tested significant for Levene's test, it was transformed $\left(\log _{10}\right.$, sqrt, $\left.x^{2}\right)$. Significance was considered as $P<0.05$.

We used the truncated product method [74] to assess the effect of multiple comparisons on the validity of $P$ values. Briefly, the truncated product method considers the distribution of $P$ values from multiple hypothesis tests to provide a table-wide $P$ value for the overall hypothesis that $P$ values were not skewed, leading to 
type 1 errors. Multiple hypothesis testing did not bias the statistical results presented here $(P<0.0001)$.

\section{Data presentation}

The effects of acclimation treatment are presented as absolute values for $U_{\text {crit }}$, metabolic rate, metabolic scope, and maximal enzyme activity, and as relative values for mRNA transcript levels. For hypothyroid treatments, the data are presented as percentage change from the normal thyroid treatments:

(normal thyroid treatment value - hypothyroid treatment value) $\times 100$.

For $\mathrm{T}_{2}$ and $\mathrm{T}_{3}$ supplementation treatments, the data are presented as percentage recovery from hypothyroid treatment

((supplemented treatment value - hypothyroid treatment value)/

$($ normal thyroid treatment value - hypothyroid treatment value) $) \times 100$.

\section{Additional files}

Additional file 1: Table S1. Pairwise planned comparison results comparing the effects of acclimation temperature between cold control (CC) and warm control (WC) groups, and of hypothyroidism between CC and cold hypothyroid $(\mathrm{CH})$ treatments and $W C$ and warm hypothyroid $(\mathrm{WH})$ treatments. $P_{\mathrm{MC}}$, Monte Carlo $P$-value; $t, t$-value; d.f., degrees of freedom; m-, muscle RNA; l-, liver RNA.

Additional file 2: Table S2. List of primers used in this study with original source (published article or Genbank accession number for which primers were designed).

\section{Abbreviations}

ANOVA: analysis of variance; ATPase $A$ : $F_{0} F_{1}$-ATPase subunit $A$; ATPase $B$ : $F_{0} F_{1}$-ATPase subunit $B$; ATPase 8/6: $F_{0} F_{1}$-ATPase subunits 8 and 6 ; COX: Cytochrome c oxidase; COX II: Cytochrome c oxidase subunit 2; COX Vb2: Cytochrome c oxidase subunit 5b2; CS: Citrate synthase; d.f.: degrees of freedom; DMSO: dimethyl sulfoxide; LDH: Lactate dehydrogenase; NRF1: Nuclear respiratory factor 1; NRF2a: Nuclear respiratory factor 2a; NRF2b: Nuclear respiratory factor 2b; nTRE: Negative thyroid response element; PERMANOVA: permutational multivariate analysis of variance; PGC1a: Peroxisome proliferator-activated receptor $\gamma$ coactivator 1-a; PGC1 $\beta$ : Peroxisome proliferator-activated receptor $\gamma$ coactivator $1-\beta$; PPARS: Peroxisome proliferator-activated receptor $\delta a$ and $\delta b ; T_{2}$ : 3,5-diiodothyronine; $\mathrm{T}_{3}$ : 3,5,3'-triiodothyronine; $\mathrm{TH}$ : Thyroid hormone; TDC: Thyroid-disrupting chemical; TRE: Thyroid response element.

\section{Competing interest}

The authors declare no competing interest.

\section{Authors' contributions}

AGL and FS conceived the project and designed the experiments; TS and KK developed the analytical protocols; AGL, TS and KK performed the experiments; AGL analyzed the data; and AGL and FS wrote the manuscript. All authors read and approved the final manuscript.

\section{Acknowledgements}

\section{Funding}

This work was funded by an Australian Research Council Discovery Grant to FS.

\section{Financial disclosure}

The funders had no role in study design, data collection and analysis, decision to publish, or preparation of the manuscript.

\section{Author details}

'School of Biological Sciences, A08 University of Sydney, Science Road, Sydney, NSW 2006, Australia. ${ }^{2}$ School of Public Health, Wadsworth Center, New York State Department of Health, Albany, NY 12201-0509, USA. ${ }^{3}$ State Key Laboratory of Urban Water Resources and Environment, IJRC PTS, Harbin Institute of Technology, Harbin 150090, China.

Received: 8 February 2013 Accepted: 19 March 2013

Published: 26 March 2013

\section{References}

1. Guderley H: Metabolic responses to low temperature in fish muscle. Biol Rev Camb Philos Soc 2004, 79:409-427.

2. Seebacher $F$ : Responses to temperature variation: integration of thermoregulation and metabolism in vertebrates. J Exp Biol 2009, 212:2885-2891.

3. O'Brien KM: Mitochondrial biogenesis in cold-bodied fishes. $J$ Exp Biol 2011, 214:275-285

4. Hulbert AJ, Else PL: Comparison of the "mammal machine" and the "reptile machine": energy use and thyroid activity. Am J Physiol 1981, 241:R350-R356.

5. Moeller LC, Broecker-Preuss M: Transcriptional regulation by nonclassical action of thyroid hormone. Thyroid Res 2011, 4:S6.

6. Silva JE: Thyroid hormone control of thermogenesis and energy balance. Thyroid 1995, 5:481-492.

7. Cannon B: Brown adipose tissue: function and physiological significance. Physiol Rev 2004, 84:277-359.

8. López M, Varela L, Vázquez MJ, Rodríguez-Cuenca S, González CR, Velagapudi VR, Morgan DA, Schoenmakers E, Agassandian K, Lage R, de Morentin PBM, Tovar S, Nogueiras R, Carling D, Lelliott C, Gallego R, Orešič M, Chatterjee K, Saha AK, Rahmouni K, Diéguez C, Vidal-Puig A: Hypothalamic AMPK and fatty acid metabolism mediate thyroid regulation of energy balance. Nat Med 2010, 16:1001-1008.

9. Erion MD, Cable EE, Ito BR, Jiang H, Fujitaki JM, Finn PD, Zhang BH, Hou J, Boyer SH, Van Poelje PD, Linemeyer DL: Targeting thyroid hormone receptor- $\beta$ agonists to the liver reduces cholesterol and triglycerides and improves the therapeutic index. Proc Natl Acad Sci USA 2007, 104:15490.

10. Hollenberg AN, Forrest D: The thyroid and metabolism: the action continues. Cell Metab 2008, 8:10-12.

11. Baxter JD, Webb P: Thyroid hormone mimetics: potential applications in atherosclerosis, obesity and type 2 diabetes. Nat Rev Drug Discov 2009, 8:308-320.

12. Dayan $C M$, Panicker $V$ : Novel insights into thyroid hormones from the study of common genetic variation. Nat Rev Endocrinol 2009, 5:211-218.

13. Skarulis MC, Celi FS, Mueller E, Zemskova M, Malek R, Hugendubler L, Cochran C, Solomon J, Chen C, Gorden P: Thyroid hormone induced brown adipose tissue and amelioration of diabetes in a patient with extreme insulin resistance. J Clin Endocr Met 2010, 95:256-262.

14. Tseng Y-H, Cypess AM, Kahn CR: Cellular bioenergetics as a target for obesity therapy. Nat Rev Drug Discov 2010, 9:465-482.

15. Pei L, Leblanc M, Barish G, Atkins A, Nofsinger R, Whyte J, Gold D, He M, Kawamura K, Li H-R, Downes M, Yu RT, Powell HC, Lingrel JB, Evans RM: Thyroid hormone receptor repression is linked to type I pneumocyteassociated respiratory distress syndrome. Nat Med 2011, 17:1466-1472.

16. Hulbert AJ: Thyroid hormones and their effects: a new perspective. Biol Rev Camb Philos Soc 2000, 75:519-631.

17. Flamant F, Gauthier K, Samarut J: Thyroid hormones signaling is getting more complex: storms are coming. Mol Endocrinol 2006, 21:321-333.

18. Moreno M, de Lange P, Lombardi A, Silvestri E, Goglia F: Metabolic effects of thyroid hormone derivatives. Thyroid 2008, 18:239-253.

19. Nelson ER, Habibi HR: Thyroid receptor subtypes: structure and function in fish. Gen Comp Endocr 2009, 161:90-96.

20. Bianco AC: Minireview: cracking the metabolic code for thyroid hormone signaling. Endocrinology 2011, 152:3306-3311.

21. Visser W, Friesema E, Visser TJ: Minireview: thyroid hormone transporters: the knowns and the unknowns. Mol Endocrinol 2011, 25:1-14.

22. Köhrle J: The deiodinase family: selenoenzymes regulating thyroid hormone availability and action. Cell Mol Life Sci 2000, 57:1853-1863. 
23. Goglia F: Biological effects of 3,5-diiodothyronine (T2). Biochem Mosc 2005, 70:203-213.

24. Norris DO: Vertebrate Endocrinology. London: Elsevier Academic Press: 2007:1-573.

25. Heyland A, Price D: Thyroid hormone metabolism and peroxidase function in two non-chordate animals. J Exp Zool Mol Dev Evol 2006, 306:551-556.

26. Heyland A, Moroz L: Cross-kingdom hormonal signaling: an insight from thyroid hormone functions in marine larvae. J Exp Biol 2005, 208:4355-4361.

27. Miller AEM, Heyland A: Endocrine interactions between plants and animals: Implications of exogenous hormone sources for the evolution of hormone signaling. Gen Comp Endocr 2010, 166:455-461

28. Heyland A, Hodin J: Heterochronic developmental shift caused by thyroid hormone in larval sand dollars and its implications for phenotypic plasticity and the evolution of nonfeeding development. Evolution 2004 58:524-538.

29. Flatt $\mathrm{T}$, Moroz LL, Tatar M, Heyland A: Comparing thyroid and insect hormone signaling. Integr Comp Biol 2006, 46:777-794.

30. Crockford S: Evolutionary roots of iodine and thyroid hormones in cell-cell signaling. Integr Comp Biol 2009, 49:155-166.

31. Paris M, Escriva H, Schubert M, Brunet F, Brtko J, Ciesielski F, Roecklin D, Vivat-Hannah V, Jamin EL, Cravedi JP, Scanlan TS, Renaud JP, Holland ND, Laudet V: Amphioxus postembryonic development reveals the homology of chordate metamorphosis. Curr Bio/ 2008, 18:825-830.

32. Eales J: lodine metabolism and thyroid-related functions in organisms lacking thyroid follicles: are thyroid hormones also vitamins? Exp Biol Med 1997, 214:302

33. Tata JR: Looking for the mechanism of action of thyroid hormone. J Thyroid Res 2011, 2011:730630.

34. Koch LG, Britton SL: Aerobic metabolism underlies complexity and capacity. J Physiol (Lond) 2007, 586:83-95.

35. Craig PM, Moon TW: Fasted zebrafish mimic genetic and physiological responses in mammals: a model for obesity and diabetes? Zebrafish 2011 8:109-117.

36. Löhr H, Hammerschmidt M: Zebrafish in endocrine systems: recent advances and implications for human disease. Annu Rev Physio/ 2011, 73:183-211.

37. Koeslag JH, Saunders PT, Wessels JA: The chromogranins and the counterregulatory hormones: do they make homeostatic sense? J Physio/ 1999, 517:643-649.

38. Izumo S, Nadal-Ginard B, Mahdavi V: All members of the MHC multigene family respond to thyroid hormone in a highly tissue-specific manner. Science 1986, 237:597-600.

39. Brent GA: Tissue-specific actions of thyroid hormone: insights from animal models. Rev Endocr Metab 2000, 1:27-33.

40. Weissman IL: Stem cells: units of development, review units of regeneration, and units in evolution. Cell 2000, 100:157-168.

41. Maniatis T, Goodbourn S, Fischer J: Regulation of inducible and tissuespecific gene expression. Science 1987, 236:1237-1245.

42. Davey K: From insect ovaries to sheep red blood cells: a tale of two hormones. J Insect Physiol 2007, 53:1-10.

43. Paris M, Brunet $F$, Markov GV, Schubert M, Laudet V: The amphioxus genome enlightens the evolution of the thyroid hormone signaling pathway. Dev Genes Evol 2008, 218:667-680.

44. Laudet $\mathrm{V}$ : The origins and evolution of vertebrate metamorphosis Curr Biol 2011, 21:R726-R737.

45. Paris M, Hillenweck A, Bertrand S, Delous G, Escriva H, Zalko D, Cravedi JP, Laudet $\mathrm{V}$ : Active metabolism of thyroid hormone during metamorphosis of amphioxus. Integr Comp Biol 2010, 50:63-74.

46. Saito M, Seki M, Amemiya S, Yamasu K, Suyemitsu T, Ishihara K: Induction of metamorphosis in the sand dollar Peronella japonica by thyroid hormones. Dev Growth Differ 1998, 40:307-312.

47. Byrne M, Ho M, Selvakumaraswamy P, Nguyen HD, Dworjanyn SA, Davis AR: Temperature, but not $\mathrm{pH}$, compromises sea urchin fertilization and early development under near-future climate change scenarios. Proc $R$ Soc $B$ : Biol Sci 2009, 276:1883-1888.

48. Sewell MA, Young CM: Temperature limits to fertilization and early development in the tropical sea urchin Echinometra lucunter. J Exp Mar Biol Ecol 1999, 236:291-305.
49. Hoegh-Guldberg O: Temperature, food availability, and the development of marine invertebrate larvae. Integr Comp Biol 1995, 35:415-425

50. Weitzel JM, Iwen KAH, Seitz HJ: Regulation of mitochondrial biogenesis by thyroid hormone. Exp Physiol 2003, 88:121-128.

51. Lin J, Handschin C, Spiegelman BM: Metabolic control through the PGC-1 family of transcription coactivators. Cell Metab 2005, 1:361-370.

52. Li J, Kinoshita T, Pandey S, Ng CKY, Gygi SP, Shimazaki K-I, Assmann SM: Modulation of an RNA-binding protein by abscisic-acid-activated protein kinase. Nature 2002, 418:793-797.

53. Ruben J: The evolution of endothermy in mammals and birds: from physiology to fossils. Annu Rev Physiol 1995, 57:69-95.

54. McNab BK: The evolution of endothermy in the phylogeny of mammals. Am Nat 1978, 112:1-21.

55. Walter I, Seebacher F: Endothermy in birds: underlying molecular mechanisms. J Exp Biol 2009, 212:2328-2336.

56. Walter I, Seebacher F: Molecular mechanisms underlying the development of endothermy in birds (Gallus gallus): a new role of PGC-1 alpha? Am J Physiol-Reg / 2007, 293:R2315-R2322.

57. Nespolo RF, Bacigalupe LD, Figueroa CC, Koteja P, Opazo JC: Using new tools to solve an old problem: the evolution of endothermy in vertebrates. Trends Ecol Evol (Amst) 2011, 26:414-423.

58. Mangiullo R, Gnoni A, Damiano F, Siculella L, Zanotti F, Papa S, Gnoni GV 3,5-diiodo-L-thyronine upregulates rat-liver mitochondrial F0F1-ATP synthase by GA-binding protein/nuclear respiratory factor-2. BBABioenergetics 2010, 1797:233-240.

59. Garcia-G C, Lopez-Bojorquez L, Nunez J, Valverde-R C, Orozco A: 3,5-Diiodothyronine in vivo maintains euthyroidal expression of type 2 iodothyronine deiodinase, growth hormone, and thyroid hormone receptor beta 1 in the killifish. Am J Physiol-Reg / 2007, 293:R877-R883.

60. Cheng S-Y, Leonard JL, Davis PJ: Molecular aspects of thyroid hormone actions. Endocr Rev 2010, 31:139-170.

61. Pandya K, Pulli B, Bultman S, Smithies O: Reversible epigenetic modifications of the two cardiac myosin heavy chain genes during changes in expression. Gene Expr 2010, 15:51-59.

62. Suzuki S, Suzuki N, Mori J-I, Oshima A, Usami S, Hashizume K: MicroCrystallin as an intracellular 3,5,3'-triiodothyronine holder in vivo. Mol Endocrinol 2007, 21:885-894.

63. Casals-Casas C, Desvergne B: Endocrine disruptors: from endocrine to metabolic disruption. Annu Rev Physiol 2011, 73:135-162.

64. Lamon L, Dalla Valle M, Critto A, Marcomini A: Introducing an integrated climate change perspective in POPs modelling, monitoring and regulation. Environ Pollut 2009, 157:1971-1980

65. Brett JR: The relation of size to rate of oxygen consumption and sustained swimming speed of sockeye salmon (Oncorhynchus nerka). J Fish Board Can 1965, 22:1491-1501.

66. Seebacher F, Walter I: Differences in locomotor performance between individuals: importance of parvalbumin, calcium handling and metabolism. J Exp Biol 2012, 215:663-670

67. Kunisue T, Fisher JW, Fatuyi B, Kannan K: A method for the analysis of six thyroid hormones in thyroid gland by liquid chromatography-tandem mass spectrometry. J Chromatogr B Analyt Technol Biomed Life Sci 2010, 878:1725-1730.

68. Kunisue T, Fisher JW, Kannan K: Determination of six thyroid hormones in the brain and thyroid gland using isotope-dilution liquid chromatography/tandem mass spectrometry. Anal Chem 2011, 83:417-424.

69. Gladden LB: Lactate metabolism: a new paradigm for the third millennium. J Physiol (Lond) 2004, 558:5-30.

70. Moyes CD, Hood DA: Origins and consequences of mitochondrial variation in vertebrate muscle. Annu Rev Physiol 2003, 65:177-201.

71. Seebacher F, Guderley H, Elsey RM, Trosclair PL: Seasonal acclimatisation of muscle metabolic enzymes in a reptile (Alligator mississippiensis). J Exp Biol 2003, 206:1193-1200

72. Dhar S, Ongwijitwat S, Wong-Riley M: Nuclear respiratory factor regulates all ten nuclear-encoded subunits of cytochrome c oxidase in neurons. J Biol Chem 2008, 283:3120-3129. 
73. McCurley A, Callard G: Characterization of housekeeping genes in zebrafish: male-female differences and effects of tissue type, developmental stage and chemical treatment. BMC Mol Biol 2008, 9:102-114.

74. Zaykin DV, Zhivotovsky LA, Westfall PH: Truncated product method for combining P-values. Genet Epidemiol 2002, 22:170-185.

doi:10.1186/1741-7007-11-26

Cite this article as: Little et al: Thyroid hormone actions are

temperature-specific and regulate thermal acclimation in zebrafish

(Danio rerio). BMC Biology 2013 11:26.

\section{Submit your next manuscript to BioMed Central} and take full advantage of:

- Convenient online submission

- Thorough peer review

- No space constraints or color figure charges

- Immediate publication on acceptance

- Inclusion in PubMed, CAS, Scopus and Google Scholar

- Research which is freely available for redistribution 